\title{
RELIGIÃO, BIOPOLÍTICA E INADIMPLÊNCIA: O PROCESSO COMO FORMA PARTICIPATIVA NA TEORIA DO RECONHECIMENTO
}

\section{RELIGION, POLITICS AND DEBITOR: THE PROCESS AS A PARTICIPATORY WAY IN RECOGNITION THEORY}

\author{
${ }^{1}$ Cristiano Da Silva Duro
}

\section{RESUMO}

Analisa-se a ligação religião-biopolítica, revelando a relação de biopoder entre credor e devedor com influência nos Direitos Humanos ao gerar dissenso e tensão social, pelo antagonismo de interesses, acirrada pela vantagem de direito material mantida pelo credor diante do devedor, o que acaba inserindo-o em estado de exceção institucionalizado, sem possibilidade de participação. Resgatando a interação entre religião e direito e delineando o que é biopoder, chegase ao devedor imune de direito fundamental. Ao final, o processo será estudado numa concepção democrática, como instrumento participativo implementador do Estado Democrático de Direito, capaz de permitir o reconhecimento e a autoinclusão.

Palavras-chave: Biopolítica, Inadimplência, Estado de exceção, Processo, Reconhecimento

\begin{abstract}
Analyzes the religion-biopolitics connection, revealing the biopower relationship between lender and borrower with influence on Human Rights to create dissent and social tension, the antagonism of interests, fierce by the advantage of right material held by the creditor and debtor, which inserting it in the state of exception institutionalized without possibility of participation. Rescuing the interaction between religion and law and delineating what is biopower, one reaches the immune debtor a fundamental right. The process will be studied in a democratic conception, as implementer participatory instrument of democratic state of law, able to allow the recognition and autoinclusão.
\end{abstract}

Keywords: Biopolitics, Delinquency, State of exception, Process recognition

\footnotetext{
${ }^{1}$ Mestre em Direito pela Pontifícia Universidade Católica - PUC, Belo Horizonte, Minas Gerais, (Brasil). Especialista em Processo Civil pelo Centro Universitário - UNA, Contagem, Minas Gerais. Professor de Processo Civil da Escola Superior de Advocacia da OAB/MG. E-mail: tutortreinamento@gmail.com
} 


\section{INTRODUÇÃO:}

Este artigo pretende analisar e sistematizar o liame entre religião, biopolítica e a inadimplência, buscando revelar a existência de relação de poder entre credor e devedor com influência direta nos Direitos Humanos ao gerar uma situação de dissenso e tensão social, pelo antagonismo de interesses, acirrada pela vantagem de direito material mantida pelo credor diante do devedor, o que acaba inserindo o inadimplente em estado de exceção institucionalizado, sem possibilidade de participação e reconhecimento.

Para tanto, iremos promover o resgate da interação entre religião e direito, delineando, em seguida, o que é biopoder e a relação de dominação entre credor e devedor que conduz este à um estado de exceção, refratário de qualquer direito fundamental. Ao final, o processo será estudado numa concepção democrática, como instrumento participativo implementador do Estado Democrático de Direito, capaz de permitir ao devedor se reconhecer e promover sua autoinclusão, viabilizando o resgate do excluído.

A guinada de pesquisa realizada pelo filosofo francês Michel Foucault nos anos 1970, revelou uma nova concepção de poder, que não mais pode ser compreendido como repressivo, mas sim marcante por sua positividade (aceito coletivamente), não apenas soberano (centralidade), mas originário de inúmeras relações de dominação, emergindo os conceitos de biopolítica e biopoder, emprestando contornos ao marco teórico deste trabalho.

Independente de direitos exibidos pela Constituição e tratados, esses tornam-se inacessíveis aos excluídos, que não detêm os meios de alcança-los em virtude de metodologia implementada na própria Constituição, que afasta o acesso daqueles que não estiverem inseridos nas estabilizações sociais promovidas.

Lado outro, a ciência processual está em constante evolução em decorrência do esclarecimento da técnica e ciência, obtido mediante a testificação (falseabilidade) dos enunciados e na investigação por meios hábeis, idôneos e adequados para consecução de resultados sobre bases objetivas.

Presta-se a crítica cientifica, veículo dialógico de verificação intelectiva, a esclarecer as obscuridades discursivas ao inquerir sobre o avanço cientifico proposto, com o cuidado de não se enveredar por críticas vulgares ${ }^{1}$, razão pela qual será o método utilizado para análise da biopolítica e a necessidade de inclusão mediante acesso aos direitos constitucionais.

\footnotetext{
${ }^{1}$ Considera-se crítica vulgar àquela que aponta pelas acomodações e contradições apenas para desprezar o objeto, sem qualquer indicação de superação. Cf. MARX, Karl. Crítica da Filosofia do Direito de Hegel. Trad.: Rubens Enderle e Leonardo de Deus. $3^{\text {a }}$ Ed. São Paulo: Boitempo, 2013.
} 
O que se pretende com o presente estudo é a autocrítica dos fundamentos e afastamento de verdades universais, estabelecidas por ideologias a serem desveladas, construindo noções argumentativas-críticas de sustentação interpretativa capazes de eliminar o discurso de autoridade em favor da capacidade de cidadania, em especial diante do proeminente papel do processo na construção do Estado de Direito Democrático.

Enfrentando a questão de dominação e acesso à direitos, será examinado o papel do processo contemporâneo e a relação estabelecida entre devedor e credor, procurando levar foco à relação de biopoder existente, cujas amarras somente podem ser desvencilhadas com o avanço da ciência processual em que o processo deve ser visto como instrumento da democracia, garantidor de direitos fundamentais ao devedor, resgatando-o do estado de exceção em que é inserido.

Seguindo essa trilha, será apresentada proposta de noção de inclusão e cidadania nessa quadra da história, diante do paradigma democrático instaurado pela Constituição vigente.

\section{RELIGIÃO: A TRADIÇÃo ROMANO-CANÔNICA E A INERÊNCIA SOCIAL AO PERDÃO}

A proximidade entre a religião cristã e direito é datada do período romano, em que imperadores cristãos, como Constantino, primeiro imperador cristão do Império, e Justiniano, quando foi mais evidente neste influxo, promoveram profunda transformação no direito romano clássico por influência religiosa (BIONDI, 1952, p. 2).

Esta transformação não ocorreu por força legislativa, mas sim no método de compreensão da legislação posta sob a ótica de valores culturais do cristianismo, como caridade, clemência e piedade, ressaltando Ovídio Baptista da Silva que esta revolução no direito bizantino foi lenta e silenciosa, por meio da reprodução da lição de grandes jurisconsultos, mas coloridas pelo espirito da religiosidade cristã (SILVA, O., 1997, p. 92).

Esta constatação também é feita por Arrigo Solmi que, trazido por Ovídio Baptista da Silva, expõe "em passagem extremamente percuciente, o espírito cristão não rejeita e muito menos repudia os textos romanos e as lições de seus juristas pagãos, limitando-se a enaltecêlos com o fermento do cristianismo, elemento catalizador dessa transformação. Os textos passam a ser iluminados por outra luz, embora permaneçam inalterados” (SILVA, O., 1997, p. 94).

A mutação legislativa influenciada por valores religiosos, nos dizeres de Paul Koschaker, cultivou-se "desde o século V, nas escolas de Direito, sobretudo do oriente, e especialmente em Beirute, professores cristãos empreenderam estudos dos juristas clássicos do 
paganismo, preparando deste modo a compilação justiniana, na qual, os digestos, coleção de fragmentos dos juristas pagãos do período clássico, constituem prova da nova atualidade do cristianismo referente à cultura pagã” (KOSCHAKER, 1955, p. 68. Tradução livre).

A religião, então, conseguiu entrelaçar-se com o Direito, de forma que, além de detalhes e instituições individuais, o julgamento civil justinianeo guardava clara conformação religiosa, permitindo a Ovídio Baptista da Silva afirmar que é de "extrema importância para os que pretendem investigar a herança romana, a formação dos institutos do direito processual moderno. Ao contrário do que em geral se imagina, nossos vínculos com o direito romano são inteiramente intermediados pelo espírito cristão" (SILVA, O., 1997, p. 91).

Foi a partir desta influência cristã que se adotaram novas noções sociológica e jurídica dos conceitos de equidade (aequitas) e da própria justiça, que somente poderia ser entendida como amor e caridade ${ }^{2}$.

O conceito estreme de equidade, no direito romano clássico, correspondia a um valor imanente ao sistema jurídico, como critério intrínseco ao sistema, ou seja, a licitude em considerar determinada norma iníqua decorria de sua contradição com o orndeamento jurídico em sentido global (SILVA, O., 1997, p. 96).

Sob influência cristã, o conceito de equidade ultrapassa a mera análise do ordenamento, alcançando verdadeiro instituto jurídico com alcance muito maior, colocando a norma diante de um mundo ideal para verificação de sua justeza. Em outras palavras, a equidade clássica, que se preocupava em incompatibilidade de uma norma com todo o sistema, passa a ser nos textos justinianeos princípio ideal de justiça humana, conformada por elementos não jurídicos de um mundo ideal (CALASSO, 1954, p. 32).

Portanto, é a partir da nova ideia de equidade e justiça, iluminadas por valores cristãos, que elementos extra-sistêmicos são utilizados na validação normativa, devendo a norma ser benigna, humana ou, em última análise, adequada à piedade cristã.

Sobrevém o racionalismo moderno, no qual "depois da redescoberta do Corpus Iuris, as alterações da consciência jurídica e política moderna pelo jusracionalismo e as reformas e revoluções que daí resultou constituem talvez o maior exemplo histórico da força revolucionária de uma teoria metodológica" (WIEACKER, 2010, p. 311).

Subjugando o valor de justiça pelo valor de segurança, polaridades antagônicas diante do iluminismo, que sustentava atuar a razão sobre dados que são fornecidos pelos sentidos

\footnotetext{
${ }^{2}$ Antônio Carlos Wolkmer e Carl Friedrich defendem a tese que Santo Agostinho teria substituído a noção de comunidade da lei, presente no pensamento antigo, pela comunidade do amor e caridade. (WOLKMER, 2006, e FRIEDRICH, 1965).
} 
(Locke, Hume), o racionalismo apresentou-se como "meio para se atingir, através da experiência e da posterior reflexão, o conhecimento da natureza" (ROSA, 2012, p. 17), de forma que no direito iluminista não é lícito interpretar uma lei em detrimento de qualquer cidadão, quando se tratar de seus bens, de sua honra ou de sua vida.

A religião foi taxada como fator preponderante que impedia a racionalização da ciência, ou, conforme Carlos Augusto de Proença Rosa (2012, p. 18), foi identificada como causa no atraso da racionalização, já que submetia o homem à crenças irracionais e fantasiosas dentro de uma estrutura de poder.

Contudo, o que ocorreu foi verdadeiro rapto do ético pela religião, pois, embora a dissociação do pensamento racional do mítico tenha promovido a emancipação gradativa do político diante do religioso, tal emancipação se resumia, em princípio, à justificação da obrigatoriedade das normas sociais pela autonomia da vontade coletiva, sem qualquer mudança no conteúdo destas normas, enquanto a fé cristã se tornou uma tradição cultural da qual o cristianismo é uma parte substancial, tendo, portanto, recebido e incorporado crenças, símbolos e valores cristãos, que influenciam o modo de perceber o mundo e o comportamento social (RAMOS, 2010, p. 60-61).

A figura do salvador e o valor do perdão se entrelaçaram de forma indissociável com a ética, pretendendo lugar como verdadeira tradição jurídica ${ }^{3}$ e, como tal, capaz de permear a compreensão da sociedade e seu agir.

Os valores cristãos persistiram influenciando a sociedade, resultando inclusive na incorporação destes valores em normas legais (a Constituição Imperial de 1824, por exemplo, estabelecia, no art. $5^{\circ}$, a religião Católica Apostólica Romana como religião oficial), de forma que, as demais religiões eram apenas toleradas.

Valores cristãos, derivados da caridade, como o sentimento de moderação, clemência e piedade, passaram, então, a informar a sociedade, como valores referenciais que influenciam o agir social, mas também o sentimento de justiça.

A influência da tradição romano-canônica produz significativos efeitos sociais, em especial quando envolvido sentimento de caridade e perdão, o que pode ser notado, de forma até curiosa, no desenrolar das negociações ocorridas entre Grécia e União Europeia, já no ano de 2015 .

\footnotetext{
${ }^{3}$ A tradição jurídica sinaliza os pressupostos históricos, culturais e políticos com os quais o sistema jurídico conjunto operacional de instituições jurídicas do ordenamento - está comprometido, sob perspectiva cultural. (Cf.
} 
Em 2009, a Grécia, descumprindo o Tratado de Maastricht para países da zona do euro, enfrentou déficit no orçamento correspondente a 13,6\% do Produto Interno Bruto - PIB (o limite previsto no tratado era de apenas 3\%), resultado de aumento exacerbado de gastos públicos, com proventos do funcionalismo público praticamente dobrando no período. Com redução da classificação de risco por agências de investimento, o que inviabilizou a obtenção de empréstimos, o governo grego decidiu ceder à política econômica de austeridade exigida pela troika ${ }^{4}$ para obter empréstimo de 110 bilhões de euros, que seriam concedidos em parcelas ao logo de três anos (CARTA, 2015), o que conduz o país à recessão profunda.

A Grécia não consegue cumprir suas obrigações, a crise se agrava e o povo é chamado às urnas para decidir sobre novas condições feitas pelos credores, sendo a "primeira vez na história das democracias europeias, uma consulta popular decorre com os bancos fechados" e, então, o oxi (não, em grego) supera o nai (sim) e "a Grécia fractura-se" (RODRIGUES, 2015) e, com ela, a zona do euro.

Tem início verdadeiro confronto entre os países do bloco econômico, com uma divisão "que respeitava aproximadamente as linhas do Império Romano. De um lado, a Europa latina, formada por países de tradição romano-canônicas como França, Itália, Espanha, Portugal e Irlanda" (GUROVITZ, 2015), revelavam a influência de uma tradição e a produção de seus efeitos sociais, defendendo, por sua tradição, o perdão do descumprimento e de parte da dívida, evitando saída da Grécia do euro-grupo.

De outro lado, liderado pela Alemanha, países de tradição protestante como Finlândia, Lituânia, Letônia, Eslováquia e Holanda estavam dispostos ao pior, com a exclusão da Grécia da zona do euro. Independente do resultado das negociações - que, ao final, prevaleceu à vontade alemã -, foi possível identificar claramente a influência da tradição no comportamento das nações e a necessidade trazida por uma cultura, por uma tradição: a do perdão.

Registre-se que, não se pretende a defesa de reestabelecer uma relação entre direito e religião atualmente, até porque a laicidade do direito é, sem dúvida, um vetor democrático imprescindível para concepção de processo que será trabalhada adiante. Procuramos desvelar, em verdade, a origem de uma tradição existente, identificando a relação de dominação entre credor e devedor e sua relação com o direito.

A busca por entender as coisas, estudando seu desenvolvimento, deve pautar o direito, pois este não entrou em vigor por uma ordem de um soberano ontem (POUND, 1941, p. 4.

\footnotetext{
${ }^{4}$ Nome dado à comissão com representantes do Banco Central Europeu, Comissão Europeia e FMI - Fundo Monetário Internacional, sob liderança de Servaas Deroose para negociação e preparação do pacote de ajuda à Grécia.
} 
Tradução livre), sendo de grande importância, ainda, revelar as relações de fundo que influenciam socialmente.

Em interessante passagem, Ovídeo Baptista da Silva afirma que "ao contrário do que em geral se imagina, nossos vínculos com o direito romano são inteiramente intermediados pelo espírito cristão que plasmou o direito do último período romano, permeando-o com outros princípios e injetando-lhe novos valores" (SILVA, O., 1997, p. 90).

Inevitavelmente, o desvelamento das tradições incorporadas à compreensão do direito representa importante passo para rompimento do instrumentalismo, pois, sob a égide da razão instrumental, o Direito encontra-se deslocado temporalmente, ou seja, a-histórico e envolvido em um paradigma da subjetividade (filosofia da consciência) que permite o discurso do salvador que se apresenta como autoridade, diante de uma (pré-)compreensão que anseia pelo perdão.

Esta compreensão exige como pressuposto uma relação de ordem material de subordinação, já que confere ao benevolente uma situação de superioridade em relação ao necessitado, àquele que acredita precisar do perdão é colocado em submissão.

A compreensão deste "(bio)poder” é essencial para revelar a situação de dominação em que o individuo é colocado, afastando-lhe dos direitos humanos fundamentais ao sujeito de direito, inserindo-o em verdadeiro estado de exceção.

Somante a partir da revelação da influência destes valores no Direito que, como alerta Streck, parcela considerável da comunidade jurídica acredita que se trata de uma racionalidade meramente (ou 'puramente') instrumental - no que não discrepa sobremodo de determinadas visões advindas da sociologia ou até mesmo da filosofia - será possível trabalhar na contramão desta tese (STRECK, 2013, p. 9), para construção de um Estado Democrático de Direito com efetivo reconhecimento e emancipação de povo.

A influência destes valores é "circunstância somente detectável na dimensão do ser-nomundo, em que a ética discursiva se coloca na pré-compreensão" (STRECK, 2013, p. 136) e o correto entendimento da relação e entrelaçamento entre valores religiosos pela ética, especialmente da figura do salvador, da necessidade e busca pela clemencia e pelo perdão, que exigem, como pressuposto, a existência de subordinação ou presença da relação de dominação é essencial para compreensão e desvelamento do biopoder na contemporaneidade, exigindo o apontamento das tradições - dimensão ética - prévias ao discurso como forma de mitigar os desvios cognitivos e se alcançar o reconhecimento do ser. 


\section{BIOPOLITICA E BIOPODER}

Mas o que é biopoder? Ao analisar as relações de poder, o filósofo francês Michel Foucault empreende uma guinada no pensamento tradicional, desviando a análise da relação Estado-cidadão (soberania), para se orientar a partir da análise do poder no âmbito da dominação, ou seja, ao invés de direcionar a pesquisa sobre a visão estatalista, de soberania e as ideologias que a acompanham, deve-se "orientar a análise do poder para o âmbito dadominação (e não da soberania), para o âmbito dos operadores materiais, para o âmbito das formas de sujeição" (FOUCALT, 2002, p. 40).

A soberania, antes conceito central de toda estrutura política-teórica moderna, era calcada em um discurso de conflitos e lutas, apresentando Foucault uma releitura desse verdadeiro cenário de guerra contínua (estado de guerra), que ocorre em virtude da igualdade entre os homens, não em um momento anterior ou futuro, mas sim através de um movimento constante no exercício do poder, que não pressupõe embate direto, ao contrário, o evita, utilizando-se de um jogo de representações, ameaças e intimidações com três diferentes momentos.

O momento inaugural, com representações calculadas - eu me represento a força do outro, represento-me que o outro se representa minha força, etc. Em seguida, num segundo momento, as manifestações enfáticas e acentuadas de vontade que demonstram que se quer a guerra, a batalha, que não pode ser renunciada. Por fim, o terceiro e último momento lança-se mão de táticas de intimidação entrecruzadas, incutindo o receio de fazer a guerra reciproco, de forma que "só ficarei tranquilo se você recear a guerra pelo menos tanto quanto eu - e mesmo, na medida do possível, um pouco mais" (FOUCAULT, 2002, p. 105).

Através de uma nova estrutura de poder, direcionada inicialmente a extrair tempo e trabalho dos corpos dos súditos (homem-máquina) - hoje em prol de condutas desejáveis e esperadas pelo corpo social - com bases em vigilância e disciplinarização na forma de obrigações crônicas que docilizam os corpos, credos de uma autonomia claramente direcionada (racionalidade instalada) pelo poder disciplinar. Isto permite à Foucault afirmar que este poder alheio à soberania é o poder disciplinar, por essencia indescritível e injustificável nos termos da teoria da soberania, já que radicalmente heterogêneo (FOUCAULT, 2002, p. 105).

Traçar noções de biopolítica ${ }^{5}$ guarda estreita relação com a investigação do interrelacionamento entre o poder e a constituição de sujeitos aptos a seguir os preceitos de uma

\footnotetext{
5 O termo biopolítica foi utilizado pela primeira vez pelo cientista político Rudolf Kjellén (1864-1922) ao compreender o Estado a partir de uma concepção organicista como "forma de vida" e "individualidade étnica". Essa forma de vida compreende grupos sociais que lutam pela existência, mas também cooperam, por meio de um
} 
estrutura social disciplinar, com múltiplas sujeições existentes e em funcionamento dentro do próprio corpo social.

Como explica José Gondra (2009), preocupa-se Foucault com um tipo de poder que pressupõe muito mais uma trama cerrada de coerções materiais do que a existência física de um soberano, revelando múltiplas relações de poder presentes em instituições sociais, nas quais foram forjados os indivíduos sociais normalizados e disciplinados.

Identificando a existência de uma série de fenômenos em que os mecanismos de poder passam a se interessar pelos corpos, ou "características biológicas fundamentais" da espécie humana, Foucault aponta para o biopoder como conjunto de mecanismos que conduzem estas características para a política, em uma estratégia de (bio)poder (FOUCAULT, 2008, p. 03).

Importante ressaltar que, Foucault não considera o biopoder excludente da disciplina e soberania, ao contrário, agrega-se à soberania a disciplina, a legislação, produzindo um direito da soberania e mecânica disciplinares que são duas peças absolutamente constitutivas dos mecanismos gerais de poder sociais (FOUCAULT, 2002, p. 45), de forma que os mecanismos de soberania e disciplina passam a serem identificados diretamente relacionados ao biopoder.

É que, o poder disciplinar cede lugar ao biopoder - poder sobre a vida - a ser exercído sobre muitos, em um jogo de exercício de poder por meio de mecanismos de regulação da população calcados em soberania-disciplina-biopoder (GONDRA, 2008, p. 185).

Assim, o direito público de soberania e a mecânica polimorfa da disciplina manipulam a norma, seus desdobramentos e objetivos de assujeitamento, distinguindo conforme seu fundamento de funcionamento, seja por uma estrutura material de incidência corporal e individual das decisões (disciplina), seja por uma estrutura forma de poder (soberania).

Peter Pelbart esclarece que "a vida e seus mecanismos entraram nos cálculos explícitos do poder e saber, enquanto estes se tornam agentes de transformação da vida. A espécie tornase a grande variável nas próprias estratégias políticas” (PELBART, 2003, p. 58).

O poder, por meio de normas, disciplina o corpo social, sendo que o saber apresentase como viés de consolidação e perpetuação para que se aja de acordo com as expectativas, enunciado através de discursos (resultantes da tensão entre poder e contrapoder - relação de dominação) eivados de pressupostos e arrogado como verdadeiro. Organiza-se o poder pelo surgimento e interação dos contrapoderes, sendo o poder constituinte de uma sociedade o conjunto de múltiplos conflitos sociais. (NEGRI e HARDT, 2006, p. 181).

procedimento dinâmico que compõe a vida do Estado, que Kjellén se propõe a estudar sob a rubrica de "biopolítica". (WALLENSTEINS, 2013). 
O discurso é a constituição de um determinado saber, permeado pelo poder, que condiciona novos saberes através de um efeito de verdade, criando entre poder e saber "um complexo indissociável, além de ser correlativos: não haverá um poder sem seu regime de verdade, como não haveria uma verdade sem seu regime de poder” (FONSECA, 2002, p. 92.).

Esse saber "verdadeiro" resultante dessa discursividade direcionada é controlado e selecionado, com claro objetivo de ser redistribuído através de procedimentos estéreis que afastam a possiblidade do aleatório (FOUCAULT, 2002a, p. 08-09).

Serviria o discurso da verdade para legitimar a exclusão social, lhe emprestando corpo, valor e validez em determinado momento da história, de forma que a exclusão é fragmento pontual da cultura que foi naturalizado (disciplinado) pelo discurso, se mostrando a exclusão como mecanismo de poder.

A relação de poder é arquitetada entre os estabelecidos (established), entendido como grupos e indivíduos que ocupam posição de poder e prestígio, sendo elevados à parâmetros sociais (modelo moral) para os demais, o que os conduz à crença de se autoperceberem como melhores socialmente. A força contrária desse poder é exercida pelos outsiders, excluídos da "boa sociedade" dos estabelecidos, sendo associados à anarquia, violência, desintegração e delinquência (ELIAS e SCOTSON, 2000, p. 7).

Dessa forma, as vidas dos outsiders tornam-se passíveis de extinção, ou seja, o biopoder permite que se mate, mas sem cometer homicídio e sem celebrar um sacrifício, de forma que possa ser matável e insacrificável, flutuando entre os seres humanos que não podem ser sacrificados e os serem não humanos, que são passíveis de sacrifício (mas não se impede o deixar morrer) (AGAMBEN, 2010, p. 83-85). O outsider não é merecedor de qualquer esforço da sociedade para ser resgatado (incluído) socialmente, pois, impregnados pelo estigma social de indisciplinados e indignos de confiança, não merecedores de integrar o corpo social, formando verdadeira massa de subcidadãos (ELIAS e SCOTSON, 2000, P. 24-27).

As tomadas de decisão excluem os outsiders da construção do discurso e apenas incute a crença que se busca sua inclusão, assim como sua disponibilidade como forma de docilizar o excluído socialmente, sendo que superação dessa herança metafísica impregnada em conceitos supra históricos conduz a questionar os sistemas de exclusão e rarefação ${ }^{6}$, em especial diante da ordem constitucional vigente construída sob princípio fundamental democrático

\footnotetext{
${ }^{6}$ Pretende-se, ao referir sobre rarefação, traçar uma ideia sobre a determinação das condições do funcionamento dos procedimentos de controle do discurso, ou, mais precisamente, sobre a "rarefação, desta vez, dos sujeitos que falam", de forma que, em algumas situações se tem um discurso relativamente livre, enquanto em outras há clara restrição, em virtude de exigências ou condições a serem satisfeitas. (FOUCAULT, 2002, p. 21-44).
} 
O cenário apresentado é incapaz de incluir o devedor - que busca pelo perdão e caridade - no debate, afastando-o a partir de sua própria pré-compreensão do direito e do processo, sendo a estrutura normativa deficiente para promover sua inclusão e, como resultado, mostra-se ineficiente e sem efetividade, gerando uma antinomia entre processo e Estado de Direito Democrático.

\section{A INSERÇÃO DO DEVEDOR NO ESTADO DE EXCEÇÃO}

A simples existência, de forma expositiva, dos direitos fundamentais na Constituição não é suficiente para considerar uma aproximação entre execução e direitos fundamentais, provocado pelo déficit de legitimidade, que impede a emancipação do devedor, com reflexo direto na sua cidadania.

Este fenômeno foi trabalhado pelos professores da Universidade de Caldas, na Colômbia, Gabriel Mendes Hincapíe e Ricardo Sanín Restrepo, que publicaram em 2012, na Revista de Derechos Humanos y Estudios Sociales, artigo intitulado La Constitución Encriptada - Nuevas formas de emancipación del poder global, por meio do qual propõem, a partir de teses eleitas, um estudo crítico em relação à economia-política e o direito.

Partindo de Antônio Negri e Michel Hardt (2006), definem a supremacia como a união permanente de várias formas de poder, conectadas por uma lógica de domínio de estruturas nacionais e novas estruturas supranacionais guiadas pelos imperativos do capitalismo que garantem sua reprodução (discurso direcionado), mas aumentam a assimetria das condições sociais, causando a completa dependência (relação de poder) do indivíduo diante do mercado.

$\mathrm{O}$ (neo)liberalismo atuaria contra a democracia por meio de três bases consubstanciadas na intensa e progressiva privação do público, despolitização dos conflitos sociais e promessa falida de inclusão na democracia, o que cuidaria de neutralizar qualquer ameaça às condições de existência do capitalismo (HINCAPÍE e RESTREPO, 2012, p. 102).

O direito liberal seria, então, despolitizado de todo tipo de conflito, para o qual a diferença e assimetria não seriam tratadas como problemas de grande iniquidade, injustiça ou opressão, mas sim como normalização controlada por uma superestrutura jurídica.

O discurso direcionado de direitos humanos se revela como axioma jurídico utilizado para docilizar os excluídos (outsiders), neutralizando os conflitos que não poderiam ser considerados como conflitos, mas apenas uma fissura na ordem social, despolitizando e asfixiando as manifestações. Assim, apontam Hincapíe e Restrepo (2012, p. 104), que “o recohecimento de todo o ser na modernidade é claramente jurídico. Se o ser não comparecer 
como rival das chaves para o direito, a sua 'personalidade' é deslocada da realidade e seu reconhecimento é negado".

O "ser” é um "não" como modelo abnegado, com a construção de um inimigo do mesmo: não-branco, não-assalariado, não-consumidor, resultando na própria ausência de reconhecimento da identidade de direitos humanos no discurso.

Tomada a Constituição política por uma metodologia interpretativa que a reduz a mero conjunto convencional de regras jurídicas, dissipando seu conteúdo por meio de uma linguagem elitista, no qual apenas um limitado número de especialistas tem condições de operar dentro da Constituição, faz perder toda comunicação política, servindo de instrumento para garantir o controle social e político absoluto (biopolítico) sobre as áreas de conflito (HINCAPÍE e RESTREPO, 2012, p. 110).

Estes conflitos ocorrem em virtude da tentativa de homogeneização social, o que, aliás, é apontado por Popper como causa da derrocada da sociedade fechada diante da complexidade social nas sociedades contemporâneas (POPPER, 1987). Rosemiro Pereira Leal aponta que a jurisdição em seu conceito de atividade de dicção e aplicação do direito por grupos humanos patrimonializados, "é tida e exercida a partir desse período como instrumento (processo) da classe poderosa e senhorial para regrar não só as suas próprias condutas, como também para impor seu imperium (mando normativo) a todos os seus súditos” (LEAL, R., 2005).

A elevação da linguagem de uma constituição política com objetivo de limitar o discurso do corpo social inviabiliza a democracia, vez que inviabiliza a utilização do discurso pleno por todos os integrantes da sociedade.

É em razão disso que Hincapíe e Restrepo propõe uma nova classificação das constituições, a ser feita sob a luz do método de eliminação democrático realizado por estrutura cindida em uma parte transparente e acessível da Constituição, aberta à sociedade e compreensível por todos; e outra parte opaca, com entrelaçamento progressivo de interpretação da linguagem que retira o sentido e conhecimento comum para torná-lo capital exclusivo de uma relação de dominação (HINCAPÍE e RESTREPO,2012, p.111).

Apesar dos autores passarem a latere do debate biopolítico, demonstra-se que a primeira parte da Constituição, tradicionalmente denominada de dogmática, é engendrada com claro objetivo de docilizar o ser social, garantindo seu direito à vida, moradia, dignidade, o que o leva a acreditar que está inserido na estrutura social, em uma dominação-opressão consentida.

Entretanto, revela a parte orgânica uma verdadeira criptografia constitucional com linguagens, procedimentos e regras de tomada de decisões dentro da Constituição que dilui progressivamente a interação social dentro de uma institucionalização de poder densa e opaca. 
Com isso, a parte criptografada da constituição desarticula (desativa) a parte transparente, tornando-a inacessível aos cidadãos.

O devedor não tem acesso aos direitos e garantias constitucionais, apesar de expressamente previstos, vez que é inserido em uma zona de penumbra ${ }^{7}$, impedindo acesso amplo e irrestrito àqueles direitos e garantias, como se pudessem os direitos fundamentais serem alienados ou renunciados, em uma verdadeira Constituição criptografada.

Autoriza-se a "escolha discricionária" daqueles princípios e garantias fundamentais que serão implementados por meio do processo, em justa contraposição ao imposto pela Constituição, de forma que, apesar de ser ato fundante do Estado de Direito, resta inaplicável ao devedor. Isto ocorre em nome da efetividade, que se revela a característica mais marcante desta visão instrumental-socializadora do processo, incrementando sua intensidade (opacidade) mesmo que em detrimento da legitimidade constitucional.

O devedor nada mais é que o outsider ou o inimigo Schmitiano, visto como verdadeiro entrave para uma "democracia substancial" (de exclusão e não plural), fundada na homogeneidade do povo de um determinado Estado, cujo ordenamento jurídico - e os próprios direitos fundamentais - deveriam apenas e tão-somente se orientar para mantença deste Estado ${ }^{8}$.

Estaria inserido, então, em um estado de exceção, que não se refere "a uma carência no texto legislativo que deve ser reparada pelo juiz; refere-se, antes, a uma suspensão do ordenamento vigente" para garantir uma lacuna normativa principiológica, capaz de afastar o devedor da democracia, enquanto não adimplida a obrigação, “onde a pura violência sem logos pretende realizar um enunciado sem nenhuma referência real" (AGAMBEN, 2010, p. 48-49).

Dentro de uma concepção de processo como relação jurídica, o estado de exceção é normatizado e transportado para um procedimento executivo ("processo" de execução) autônomo, instrumento da jurisdição em busca da pacificação social e restabelecimento da ordem social, através da violência e subsunção normativa, que pretendia unicamente forçar o devedor ao cumprimento da obrigação inadimplida, tornando-se, evidentemente, prescindível o incauto contraditório, assim como a compreensão.

Resume-se o quadro pela célebre frase de Chiovenda de que "o processo deve dar, quando for possível praticamente, a quem tem um direito, tudo aquilo e exatamente aquilo que

\footnotetext{
${ }^{7}$ A expressão é de Hart (HART, H., 2012) e utilizada por Lenio Streck, tendo por significado um espaço aberto inalcançável pela regra, que torna inevitável o poder discricionário do julgador.

${ }^{8}$ Importante esclarecer que Schmitt promovia distinção entre os direitos fundamentais relacionados aos membros da comunidade política, as garantias de institutos relacionados às instituições de direito privado e as garantias institucionais, ligadas às instituições de direito público, sendo que esta última era essencial para garantia dos direitos de liberdade, motivo pelo qual deveria prevalecer sobre todas as outras (SCHMITT, 2006).
} 
ele tenha direito de conseguir"(CHIOVENDA, 1960, p. 67), neste caso, sempre entendido como o credor, olvidando-se que também o devedor é sujeito constitucional, ou seja, têm direitos a serem observados e, mais do que isso, tem direito de participar para emprestar legitimidade ao procedimento.

Contudo, neste processo como relação jurídica de execução, a parte devedora, em suma, é substituída pelo paternalismo estatal representado pela figura do Estado-Juiz, que, preenchendo o anseio de figura do salvador, proverá o lugar do devedor no círculo de legitimação dos atos, com fundamento em seu sentimento jurídico-pessoal (filosofia da consciência) e exercendo a atividade jurisdicional em função da sabedoria e sensibilidade, sempre atento à instrumentalidade do processo e seguindo a trilha traçada pelo processo como relação jurídica (Bülow).

Convém notar que, não foram as elucubrações da relação publicística-processual capazes de explicar como se poderia controlar a atividade jurisdicional criadora de um direito que era exercício estatal do império, mais ainda, quando o devedor era propositadamente afastado deste processo, em última análise, emocional ou sentimental, derrubando o pilar de sustentação sobre a legitimidade da decisão fora do Estado Social.

O procedimento executivo, ainda como em Roma, vem sendo visto como reestabelecimento unidirecional de uma pretensa estabilidade social, ou seja, é "expediente que atribui segurança aos fatos decididos pela força da espada de Têmis. O Estado usa da força, mas a usa sob a certeza que o Direito lhe confere (ou pretende)"(MEIRELES, 2008, p. 97). Depois de inserido o devedor no estado de exceção, retirando-lhe a possibilidade de declaração de vontade, a aceitação das condições que lhe são impostas é único meio de participação, e quebra do elo de dominação, para se inserir novamente no corpo social, o que torna, por consequência lógica, pretensa conciliação impossível (BENEDETTI, 2014, p. 77-103).

O processo, por isso, não pode servir de mero instrumento de uma concepção de jurisdição incapaz de servir à democracia, propiciando vícios discursivos entre os sujeitos processuais, causados pela inserção e, por consequência, ausência de autonomia, de uma das partes em um estado de exceção (BENEDETTI, 2014, p. 77-103), impondo uma nova construção teorica de processo, suficiente para execer a inclusão e reconhecimento.

Este espaço-discursivo constitucionalizado (processo) ideal exige respeito e observância à todos os direitos fundamentais, como forma de concretização dos direitos humanos do devedor, em um ambiente verdadeiramente democrático, única forma de desmantelar a relação de poder entre credor e devedor neste típico cenário de neoliberalismo processual. 


\section{DEMOCRÁCIA E PROCESSO}

O movimento de constitucionalização dos direitos pós-segunda guerra deslocou a Constituição para assumir o papel central do ordenamento jurídico como fonte de direito e também como núcleo hermenêutico do interprete, exigindo desenvolvimento de uma atividade interpretativa constitucionalizada do direito infraconstitucional, que deve guardar estreita relação com os princípios e garantias fundamentais.

Assenta Rosemiro Pereira Leal que, a atividade construtora da lei no Estado Democrático de Direito exige a observância à principiologia processual constitucional para que lhe seja emprestada legitimidade, permitindo às maiorias e minorias isonomia discursiva no exercício do contraditório e da ampla defesa (LEAL, R., 2012, p. 45-46). É o caminho seguido também por Canotilho, que assinala somente ser possível um Estado Constitucional sustentado por fundamentos não metafisicos a distinção da legitimidade do direito dos direitos fundamentais e do processo legislativo, assim como assegurar igual participação democrática na formação da vontade popular (CANOTILHO, 1998, p. 96).

Apenas através de elementos essenciais, como escolha dos seus representantes pelo voto direto, secreto e igual, a participação popular na solução de problemas e questões da nação, mas, especialmente, pela legitimação do exercício do poder pelo povo (BRÊTAS, 2010, p. 6364), com respeito às minorias, pode se falar em democracia, já que em sistemas sociais complexos, caracterizados por diversidade de interesses econômicos, políticos, religiosos e culturais (CATTONI DE OLIVEIRA, 2001, p. 219-221), a participação deve ser necessariamente considerada na produção do ato estatal.

Importante lembrar que, dentro da noção de Estado, sendo o poder mais que qualidade ou atributo do Estado, mas condição de existência, além de uno e indivisível (BRÊTAS, 2010, p. 59), emana exclusivamente do povo $^{9}$ - sujeito constitucional - e, em última análise, é o povo legitimador da existência do próprio Estado. Destarte, a legitimação da Constituição somente pode ocorrer por meio da participação do povo em sua interpretação, abrindo por completo o discurso. O direito processual contemporâneo, não diferente, tem em sua gênese o Estado de Direito Democrático e nos princípios constitucionais “definidos nas garantias da ampla defesa,

\footnotetext{
${ }^{9}$ Ronaldo Brêtas, com base em Jorge Miranda, é preciso ao apontar: "Como povo, há de entender a comunidade política do Estado, composta de pessoas livres, dotadas de direitos subjetivos umas em face de outras e perante o próprio Estado, fazendo parte do povo tanto os governados como os governantes, pois estes são provenientes do povo, sejam quais forem suas condições sociais, todos obedientes às mesmas normas jurídicas, sobretudo à Constituição, que é o estatuto maior do poder político”. (BRÊTAS, 2010, p. 59)
} 
do contraditório e direito ao advogado e isonomia” (LEAL, R. 2012, p. 54) reunidos pelo instituto do devido processo.

Tornou-se o processo espaço discursivo para participação e inclusão social mediante debate das partes, num plano poliárquico, ou seja, é uma estrutura normativa constitucionalizada que tem por escopo viabilizar acesso ao discurso político por todo cidadão com submissão aos princípios jurisdicionais e constitucionais.

Trata-se de garantias da própria sociedade como comunidade de jurisdicionados frente ao Estado, pois uma verdadeira democracia processual somente pode ser obtida pela comparticipação, com assunção de corresponsabilidade social e política por todos os envolvidos, estruturando de forma constitucionalizada procedimentos de inclusão e emancipação sociais tecnicamente eficientes (NUNES, 2012, p. 197).

Os direitos fundamentais processuais não permitem uma visão excludente (solipsista) do procedimento democrático, uma vez que o pluralismo e a possibilidade de ocorrência de um dissenso racional de valores é preceptor democrático, não podendo ser atribuído "a qualquer guardião de uma única concepção e interpretação privilegiada de uma suposta ordem concreta de valores", o que, aliás, permitiu o reforço da concepção estatal vigente na Alemanha Nazista. (NUNES, 2012, p.79-94). Na sociedade democrática a valoração da conduta é feita por ela própria, através dos processos admitidos na lei fundante da ordem jurídica, não podendo ser declinada a um único e exclusivo individuo participante do procedimento, pois os sistemas democráticos se caracterizam pelo pluralismo, e não monólito, representando verdadeira contradição lógica pressupor a inexistência dessa pluralidade. (GONÇALVES, 2012, p. 163164)

Historicamente, a construção unilateralmente pelo Estado (established) do discurso, ainda que de acordo com o direito vigente, emprestava ao processo discursivo estrutura propícia às práticas autoritárias (direcionamento), o que não tem lugar diante da consolidação dos direitos e garantias individuais, que ganharam maior relevância após as duas grandes guerras mundiais, quando a visão científica conduziu à constitucionalização do processo, exigindo-se a comparticipação na formação das decisões políticas e jurisdicionais.

Destarte, por meio das argumentações trazidas é possível extrair noção sobre o que seja o processo constitucional em superação à concepção de processo como relação jurídica ou instrumento da jurisdição, expandindo os limites sistêmicos por meio do devido processo legal, tornando-se instrumento de implementação de direitos fundamentais e verdadeira realização da cidadania. 


\section{AÇÃO, INCLUSÃO E CIDADANIA}

Inicialmente, partindo de Hannah Arendt (2010), deve ser feita uma distinção entre o labor, o trabalho e ação, aspectos da condição humana - considerada como formas de vida que o homem impõe a si mesmo para sobreviver - de forma que esse conjunto de atividades de reprodução humana (vita activa) seja capaz de distinguir a busca por um reconhecimento (inclusão), na tensão da relação de dominação sobre a vida.

O labor deve ser considerado aquele que "não deixa atrás de si vestígio permanente", mas produz aquilo que lhe é vital (ARENDT, 2010, p. 101), razão pela está vinculado à reprodução metabólica do ser; o trabalho é exercido pela capacidade raciocinada de produzir (techné) bens com durabilidade, objetividade e reversibilidade, por meio de atividade repetitiva de rotinas da vida; e a ação (praxis) é a que se realiza sem a matéria, exigindo pluralidade para prática política. Essa bios-polytikos (vida reflexiva) permite a construção da identidade subjetiva individual por meio do reconhecimento recíproco entre sujeitos, ou seja, "só quando dois indivíduos se vêem confirmados em sua autonomia por seu respectivo defrontante, eles podem chegar de maneira complementária a uma compreensão de si mesmos como um Eu autonomamente agente e individuado" (HONNETH, 2003, p. 119-120).

Somente a partir da tensão na relação de domínio (conflito) poderá originar a luta por reconhecimento (direito de resistência), a qual vincula uma força moral capaz de impulsionar o

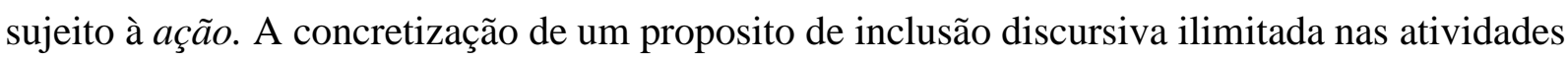
políticas (bios-polytikos) é capaz de permitir a inclusão em uma sociedade democrática em que a diferença e desacordo são seus traços fundamentais, ao contrário da homogeneidade e da similitude (CITTADINO, 2004, p. 77-78).

Considerar a existência de um povo homogêneo, naturalizando a presença dos outsiders sob um viés historicista-comunitarista milita em desfavor da democracia (inclusão) e não contribui para a emancipação, já que retira do povo a responsabilidade por suas escolhas fazendo prevalecer a tática do dominar e do submeter. (POPPER, 1987, 277-287).

O espaço jurídico-dialógico (processo) estabelecido pelo Estado Constitucional Democrático permite, por meio da linguagem, a ampla participação dos cidadãos mediante a principiologia constitucional do contraditório, ampla defesa e isonomia, gerando faixas de discussão que autorizam a plena fiscalidade política de uma Administração Governativa, garantido pelo direito-de-ação. Busca-se, com isso, "perseguir a legitimação de uma instituição processual constitucionalizada de controle irrestrito dos procedimentos político-jurídicos como diretriz principiológica das regras de relacionamento na elaboração e operacionalização de um Sistema de Direitos” (LEAL, R. 2012, p. 100) 
Nesse cenário, é permitido ao sujeito social divergir discursivamente durante a tomada de decisão, garantindo o verdadeiro exercício da cidadania, princípio essencial democrático, pois "não há cidadãos sem democracia ou democracia sem cidadãos" (CARVALHO, 2008, p. 818) e somente é possível alcançar a cidadania pela inclusão, que exige:

A extensão à todos do discurso dentro do espaço jurídico-dialógico permite a pluralidade de participação na bios-polytikos, de forma que sejam incluídos, descriptando a Constituição para que, através da participação, passem todos sujeitos sociais a terem efetivo acesso à sua parte transparente.

E dessa forma, afastam-se os papeis salvacionistas e paternalistas a terceiros, já que será assumida por cada cidadão a responsabilidade pelos princípios elementares de sua vida em comum na sociedade, não podendo mais recorrer a uma autoridade transcendente que o alivie de suas decisões (GÜNTHER, 2002, p. 109, apud NUNES, 2012, P. 197).

Ao contrário, o Estado constitucional democrático assegura, "mediante balizas processuais constitucionais (princípios constitucionais), uma participação constante e efetiva dos sujeitos de direito, que a estes permite uma colaboração na formação dos provimentos (leis, decisões judiciais, atos administrativos) dos quais sofrerão os efeitos" (NUNES, 2012, p. 197)

Como explica Honneth, os indivíduos aprendem a verem-se a si mesmos como membros plenos e especiais da comunidade ao ir gradualmente se assegurando das capacidades e necessidades específicas que os constituem como personalidades mediante a reação de apoio de seus parceiros generalizados da interação.

\section{CONCLUSÃO}

Somente é possível falar em democracia com a inclusão de todo sujeito social, não podendo ser admitida a existência de outsiders sem acesso aos direitos e garantias expressos na Constituição, em virtude de uma parte criptograda desta, que desativa a parte transparente, afastando dos "não iniciados" a possibilidade discursiva de interação com a sociedade na tomada de decisões e de usufruto de seus direitos.

Revela-se que, a relação maerial existent entre devedor e credor acaba por estabelecer verdadeira relação de biopoder, cujas amarras são transportadas para o processo, inserindo o devedor em verdadeiro estado de exceção, sendo-lhe negada observância às garantias fundamentais basilares do Estado Democrático de Direito.

Emerge, então, o processo em sua nova concepção constitucionalizada, distinguindose dos procedimentos - espécie do gênero processo - e rompendo com as barreiras anteriormente colocadas, que o limitava apenas à função jurisdicional estatal, para se mostrar 
verdadeiro instrumento democrático, ampliando, pelo devido processo legal, a discursividade social, em uma interpretação aberta da Constituição, de forma a possibilitar a inclusão o socialmente excluído.

Dessa forma, o processo se torna meio de permitir o acesso à parte anteriormente criptograda da Constituição - exigindo o reconhecimento de um espaço jurídico-dialógico, concatenado a partir dos princípios do contraditório, ampla defesa e isonomia, permitindo ampla participação e fiscalidade pelo povo, tornando permeável a sociedade com fins de possibilitar a auto-inclusão discursiva daquele antes excluído, com verdadeiro reconhecimento.

\section{REFERÊNCIAS}

AGAMBEN, Giorgio. Homo Sacer: o poder soberano e a vida nua I. Belo Horizonte: UFMG, 2010

ARENDT, Hannah. A condição Humana. $8^{\mathrm{a}}$ ed. Trad. Roberto Raposo. Rio de Janeiro: Forense, 2010

BENEDETTI, Andréa Regina de Morais. Anistia, Inimigo e Judiciário: (im)possibilidades do acordo político no Estado de Exceção. Revista da Faculdade de Direito da UFMG, Belo Horizonte: $n^{\circ}$ 64, p. 77-103, jan./jun. 2014

BIONDI, Biondo. Diritto Romano Cristiano. Vol. I. Milano, 1952

BRÊTAS, Ronaldo de Carvalho Dias. Processo constitucional e Estado Democrático de Direito. Belo Horizonte: Del Rey, 2010

CALASSO, Francesco. Medio Evo Del Dirrito. Milano: Giuffrè, 1954

CANOTILHO, José Joaquim Gomes. Direito Constitucional e Teoria da Constituição. $3^{\mathrm{a}}$. ed. Reimpressão. Lisboa: Almedina, 1998

CARTA, Gianni. Grécia: entenda a crise e conheça o novo governo. Carta Capital, 31/01/2015. Disponível em <http://migre.me/rQ9mK>, acessado em 05 de agosto de 2015, às $16: 32$

CARVALHO, Kildare Gonçalves. Direito Constitucional. 14 ${ }^{\text {a }}$ Ed. Belo Horizonte: Del Rey, 2008

CATTONI DE OLIVEIRA, Marcelo Andrade. Direito Processual Constitucional. Belo Horizonte: Mandamentos, 2001

CHIOVENDA, Giuseppe. Istituzioni di Diritto Processuale Civile, Vol. I. Napoli: Jovene, 1960 
CITTADINO, Gisele. Pluralismo, Direito e Justiça Distributiva: elementos da filosofia constitucional contemporânea. $3^{\text {a }}$ Ed. Rio de Janeiro: Lumen-Juris, 2004

ELIAS, Nobertson. SCOTSON, John L. The established and the outsiders. A sociological equiry into community problems. Londres: Frank Cass \& Co Ltd., 1994

FONSECA, Ricardo Marcelo. Modernidade e Contrato de Trabalho: do sujeito de direito à sujeição jurídica. São Paulo: LTr, 2002

FOUCAULT, Michael. A ordem do discurso. São Paulo: Loyola, 2002a . Em defesa da sociedade. São Paulo: Martins Fontes, 2002

Paulo, 2005 . Multidão - Guerra e democracia na era do Império. Rio de Janeiro/São . Segurança, Território e População. São Paulo: Martins Fontes, 2008

FRIEDRICH, Carlos Joachim. Perspectiva Histórica da Filosofia do Direito. Rio de Janeiro: Zahar, 1965

GONÇALVES, Aroldo Plínio. Técnica Processual e Teoria do Processo. $2^{\mathrm{a}}$ ed. Belo Horizonte: Del Rey, 2012

GONDRA, José G. Tomar Distância do Poder in Para uma vida não-fascista (Coleção Estudos Foucaultianos). Belo Horizonte: Autêntica Editora, 2009

GÜNTHER, Klaus. Responsabilização na sociedade civil. In Novos Estudos CE-BRAP, nº. 63, p. 105-118, jul. 2002.

GUROVITZ, Helio. Alemanha 7 x 1 Grécia. Portal G1, 2015, Disponível em <http://migre.me/rQ9o9>, acessado em 13/07/2015.

HINCAPÍE, Gabriel M. RESTREPO, Ricardo S. La Constitución Encriptada. Revista de Derechos Humanos y Estudios Sociales. Caldas: Universidade de Caldas, 2012.

HONNETH, Axel. Luta por reconhecimento: a gramática moral dos conflitos sociais. São Paulo: Editora 34, 2003

KOSCHAKER, Paul. Europa y el derecho romano. Madrid: Editorial de Dereho Reunidas SA, 1955

LEAL, Rosemiro Pereira. Processo Civil e Sociedade Civil in Revista Virtuajus, Belo Horizonte, ano 4, n.2, dez.2005. Disponível em <http://migre.me/tvQC6>. Acessado em 28/01/2015.

LEAL, Rosemiro Pereira. Teoria Geral do Processo - Primeiros Estudos. $11^{\text {a }}$ Edição. Rio de Janeiro: Forense, 2012 
MARX, Karl. Crítica da Filosofia do Direito de Hegel. Trad.: Rubens Enderle e Leonardo de Deus. $3^{\text {a }}$ Ed. São Paulo: Boitempo, 2013

MEIRELES, Gustavo Fernandes. A Importância da Epistemologia Jurídica da Superação do Senso Comum Douto no Âmbito Jurídico. Revista Opinião Jurídica. Fortaleza: Unichristus, ano XI, nº. 15, p. 97, 2013.

MERRYMAN, John Henry. PRÉREZ-PERDOMO, Rogelio. The Civil Law Tradition: An introduction to the legal systems of Europe and Latin America. $3^{\mathrm{a}}$ ed. California: Stanford University Press, 2007

NEGRI, Antonio. HARDT, Michael. Imperio. Rio de Janeiro: Record, 2006

NUNES, Dierle José Coelho. Processo Jurisdicional Democrático. Curitiba: Juruá, 2012

PELBART, Peter Pál. Vida capital: ensaios de biopolítica. São Paulo: Iluminuras, 2000

POPPER, Karl R. A Sociedade Aberta e Seus Inimigos: A preamar da profecia. T.2. São Paulo: EDUSP, 1987

POUND, Roscoe. What of Stare Decisis?. Fordham Law Review. Vol. X. New York: Hefferman Press, 1941

RAMOS, Marcelo Maciel. Direito e Religião: reflexões acerca do conteúdo cultural das normas jurídicas. Revista Meritum. Belo Horizonte: FUMEC, vol. 5, p. 60-61, jan./jun. 2010

RODRIGUES, Pedro Caldeira. O Sobressalto Grego. Lisboa: Editora Arranha-Ceus, 2015.

ROSA, Carlos Augusto de Proença. História da Ciência: a ciência moderna. $2^{\mathrm{a}}$ Ed. Vol. II, Tomo I. Brasília: FUNAG, 2012

SILVA, Ovídio Araújo Baptista da. Jurisdição e Execução na Tradição Romano-Canônica. $2^{\mathrm{a}}$ Ed. São Paulo: RT, 1997

STRECK, Lenio Luiz. O que é isto - decido conforme minha consciência: $4^{\mathrm{a}}$ ed. Porto Alegre: Livraria do Advogado, 2013

WALLENSTEIN, Sven-Olov. Introduction: Foulcault, Biopolitics, and Governmentality. In: NILSSON, Jakob. WALLENSTEIN, Sven-Olov. Foulcault, Biopolitics, and Governmentality. Södertörn Philosophical Studies 14, Stockholm 2013.

WIEACKER, Franz. História do Direito Privado Moderno. $4^{\mathrm{a}}$ ed. Lisboa: Fundação Calouste Gulbenkian, 2010

WOLKMER, Antônio Carlos. Sintese de Uma História das Ideias Jurídicas: da antiguidade clássica à modernidade. Florianópolis: Fundação Boiteux, 2006 